Journal of Engineering and Applied Sciences 15 (5): 1175-1179, 2020

ISSN: 1816-949X

(C) Medwell Journals, 2020

\title{
Explore the Relationship between Human Resources Information Systems with Strategic Human Resources Planning to Attain Competitive Strategy
}

\author{
Hanady Al-Zagheer and Samer Barakat \\ Department of Management Information Systems, \\ Applied Science Private University, Amman, Jordan
}

\begin{abstract}
This study is attending to propose a model linking between human resources information systems and strategic human resources planning in order to achieve competitive strategy advantages for business organizations, implementing the proposed model will continuing the strategic direction of human resources policies and completing their various aspects which leads companies to compete and differentiate in the globalization. Taking into consideration the latest technological developments in the world and their uses when determining training strategies and employing them to develop workers who do their jobs better, the need to adopt a new knowledge culture based on the culture of educational organizations in companies communications that support training and development programs are based on the fundamentals of continuous learning and creation the supporting internal environment is sustainable. The proposed model also emphasis the need to pay attention to the design of specialized work in organizations and their requirements in order to be consistent with indicators of the actual need of these companies and meet the requirements of global competition in this field.
\end{abstract}

$\underline{\text { Key words: Human resources, information systems, planning, competitive strategy, specialized, fundamentals }}$

\section{INTRODUCTION}

There is a fair amount of information that might be useful to new employees once they join the organization and to other individuals who may have to make very different kinds of decisions but might still need to know something about current human resources in the organization. The need for this kind of information in an easily accessible and ready to use form is at the heart of human resource information systems.

Human resources management strategies aim at enhancing the individual's perceptions and knowledge, increasing the options available to him, thereby improving their skills, creating opportunities for creativity and ensuring their human rights and participation positively and constructively at work.

The efficiency of human resources management strategies is a reflection of how the organization is dealing with major problems, human resources and develop appropriate solutions to these problems where good performance cannot be achieved without resorting to appropriate strategies to manage their human resources in addition to that updates. The formulation of these strategies requires the creation of a vision for the future which will positively affect the performance of employees. Organizational performance is the final outcome of all activities carried out by the organization and results in performance excellence and the organization's interest in raising the level of the organization's staff to be more sustainable.
It has been found that all those responsible for the organizations in all their names, sizes and objectives are interested, performance is clearly not a reflection of the capabilities and motivation of everyone in the performance of their organizations.

And the amount of work done by him but rather the reflection of the performance of these organizations and their degree of effectiveness and evaluation of their work. One of the main approaches to improving the quality and quality of employee's performance is the strategies adopted and adopted by the human resources department of these organizations.

\section{Literature review}

Human Resources Information Systems (HRIS): The discussion concerning human resource information systems relates to the privacy of the information it contains. A prime reason for an organization to install a HRIS is to make it easier to find information. This ease of accessing information also has a downside: it is easier for unauthorized individuals to obtain private information (both company personnel information) or for system users to accidentally disclose private information, some laws exist that provide penalties for illegally obtaining certain kinds of employee information but this does not always stop it from happening an employee whose employer has accidentally divulged her performance appraisal history (when only her salary history was supposed to be released) to a bank loan division will not be any less upset

Corresponding Author: Hanady Al-Zagheer, Department of Management Information Systems, Applied Science Private University, Amman, Jordan 


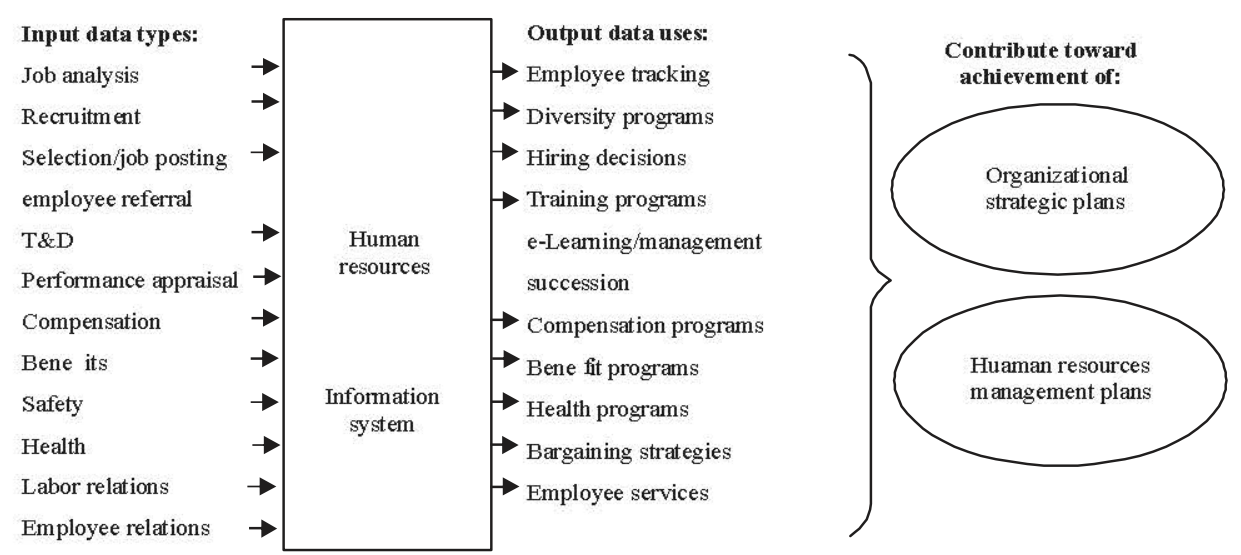

Fig. 1: Human resource information system designed for one organization

if it was an accident. Organizations should make every attempt to provide safeguards against revealing private information whether illegally or accidentally obtained. Protections such as system passwords, restricting access to confidential information on a need to know basis and physically locking up files at the end of each day are just the first steps in protecting the organization reputation, its competitive position and its legal liability, other issues that need to be considered include carefully defining and limiting user authorization, verifying that a user is actually the person authorized to use the system, encoding the data if it is transmitted and when it is stored and using audit trails that provide a clear picture of who accessed what and when. By incorporating some or all of these ideas, the HRIS system should be secure.

HRIS modules: The modular approach to HRIS facilitates a user to look for his data of interest restricting his focus on some elements of the data. It is directed to some specific function of HRM. For HRP in an organization, there may be specific requirement of a module while for training and development, there may be another. To decide about specific requirement of HRIS modules, it is always essential to do a need analysis. Needs are specific to an organization. Therefore, needs of one organization may not match with another, unless these are generic in nature and intended to address only some technical requirements like, security user interface and navigation, standards, data integrity, validation, etc., to ensure proper HRIS in an organization vis-a-vis appropriate selection of HRIS modules, it is important to integrate needs with the technology strategy of an organization. For example, if in near future, your organization decides to change the technology platform, then to decide about HRIS modules, you have to ensure its compatibility with a changed platform or else, you will soon identify obsolescence of your HRIS. Similarly, to perform need analysis for HRIS, it is also essential to integrate it with your corporate strategy. If your corporate strategy limits its focus only on automation of payroll in HRIS, you may only look for the best of those modules which address to payroll automation requirement. But if you're corporate strategy is to go for enterprise wide applications then look for those HRIS modules that support enterprise wild applications. Most of the organizations today are re-engineering their business process which calls for a holistic HRIS approach, rather than specific payroll or employee information. Going for enterprise wide systems is always a better choice for important strategic decisions about HR.

HRIS need analysis is also integrated with critical success factors within an organization. This is ensured by duly taking into cognizance critical inputs from different cross functional teams. Such cross functional teams will include HR, finance, line mangers and IT professionals. Such critical inputs facilitate documentation of various expectations and relate such expectations of the HRIS requirements. Once need analysis is performed, it is better to go for a final sign off of the requirements by participating cross functional team members. This ensures documented concordance and commitment from the end users during subsequent implementation and operation of HRIS. A final documentation is done for subsequent selection of HRIS vendors.

Mondy and Noe human resource information systems model: Mondy and Noe (2005) propose a model for human resource information systems they state that firms are realizing that a properly developed HRIS can provide tremendous benefits to the organization. While many HR directors and managers at small organizations shoulder HRIS in addition to their many other responsibilities, larger organizations have specialized staff to address technology issues. Figure 1 presents an overview of the 
human resource information system designed for one organization. Utilizing numerous types of input data, the HRIS provides many types of output data that have far-reaching human resources planning and operational value. The HRIS integrates all human resource information into the system.

\section{MATERIALS AND METHODS}

Strategic human resource management: Through strategic planning efforts incorporate the specific actions that will be taken to bring organizational goals to life, drawing guidance from a detailed assessment of the organization's internal and external environments and the participation of interested parties from the organization and its community. Bryson echoes other theorists in arguing that public and nonprofit organizations face uniquely turbulent environments necessitating coordinated action. Organizational leadership must think in terms of internal operations and external environment to translate potential organizational responses into goals that are coordinated and serve to mesh organizational efforts with environmental demands.

Sperceived barries to startegic planning: Wright and Boswell (2002), suggested three major barriers to planning in nonprofit organizations that may echo difficulties with public sector strategic planning: the skill level of managers charged with planning, the diversity of agendas for the various stakeholders and concerns about the rigidity of formal plans.

First, staff may be relatively unskilled in planning and managem ent techniques, just as traditional workforce planning efforts were often relegated to centralized human resource departments, other planning efforts might be comport, metalized, delegated as the domain of a particular department in an agency or retained at a certain level of organizational decision making, under these circumstances, little active participation would be required from line supervisors, however with strategic planning, workforce planning is integrated with all other aspects of operations and in consideration of other environmental factors.

This means that line managers as well as human resource specialists need to be familiar with strategic planning, generally and with the issues attendant to traditional workforce planning, taining is necessary in the techniques of planning and environmental assessment methods, even if employees (and outside participants) are familiar with the general concepts of strategic planning, the complexity of the data to be considered may be overwhelming, the addition of complex modeling programs to manage all of the detail about the organizations environment, staffing levels and characteristics, range of project types, varying time lines and diverse bench marking criteria could hinder active participation by who are unfamiliar with or intimidated by statistical analysis.

Second, the diversity of goals, values and interests of the people associated with the organization makes planning difficult for example, bringing out the perspectives of clients, donors (taxpayers), volunteers and board members (political decision makers) can be difficult enough, meshing these views may require some vagueness in goals and objectives to limit internal conflict between organization stakeholders, unfortunately, ambiguity in goals and objectives makes it difficult to develop a series of actions as a result.

Organizations, the only certainty is that demand will exceed resources. A third problem is that in nonprofit sector organizations, staff members and volunteers may resist planning because it seems a bit too corporate or businesslike rather than client responsive, they echo concerns frequently expressed by public sector administrators that formal plans have the potential of limiting flexibility of action or alternatively, "imposing bureaucracy" on adaptive or innovative activities, Aswathappa (2002).

Additional problems with strategic planning may stem from previous efforts, unfortunately, it is not unusual for public managers to find themselves buffeted by "flavor of the week" management trends.

Strategic planning has often been treated as one such faddish effort, suddenly an agency is asked to develop a plan by a legislative body or executive branch official; consultants are hired and committees are formed and day long work sessions are scheduled, mid level managers are thrown together with a sprinkle of line level supervisors to develop a mission statement, goals and objectives in an $8 \mathrm{~h}$ retreat the comments are scribbled on large pieces of paper for the group to see and then carefully transferred to a document that will become.

Another problem that may frequent planning efforts is over planning. The highly detailed scheduling of implementation efforts or the development of overly structured plans can often impede organizational responsiveness. Some individuals do tend to invest heavily in the written plan and limit their efforts exclusively to those activities that are specifically detailed, thereby limiting innovation and adaptability. The organization's environment will still be fluid even after a plan is in place, so, a general focus on goals and willingness to let the organization respond to environment cues is important. Managers should have the latitude to respond to shifts and be comfortable with change and variety while recognizing that even small decisions can lead to larger outcomes for good or ill.

Role of HR strategy in strategic management: When used properly, a HRIS can be a valuable tool for strategic 
planning and implementation. HRIS information should help decision makers had better understand how human resource management a valuable competitive tool can be. It can be used to monitor morale, efficiency and labor costs. It can be used to plan for the future human resource needs of the firm or to anticipate changes in the competitive environment. Its use is limited only by the extent to which the organization uses it to make strategic human resource decisions. Many firms are beginning to realize the value of using human resources to gain a strategic advantage-or a unique skill or competence that other firms do not have.

It often falls upon human resources managers to help top management recognize the need for and value of a HRIS. Since, the costs for acquiring and implementing such a system can be substantial, showing the benefits the firm including how the system can help strategically align the organization with its goals is an important step in winning top management support. To do this, the HR manager needs to think in business terms to determine exactly how a HRIS can help achieve business objectives. First, the human resource manager must identify ways a HRIS system can support the organizational business goals and how using a HRIS can help achieve these goals. Then, the HR manager can develop a HRIS that is tailored to meeting these goals and introduce a deployment strategy for the HRIS. By adopting a value-added perspective such as this, it is possible to link the HRIS directly to the organization,s key business strategies.

\section{RESULTS AND DISCUSSION}

Competitive strategy: Competitive strategy: defined as a position attaine by a business unit and perceived by its customers when it is compared with its competitors. They may be characterized as lower cost or differentiation and focus competitive strategy (Porter, 1998).

Proposed model: Based on Mondy and Noe human resource information systems model, Pfeffer strategic human resource planning practices and porter competitive strategy, the researcher's model is developed Conner and Ulrich (1996) (Fig. 2).

\section{Model terms definition}

Career planning: Facilitate professional/career development planning for both the individual and the

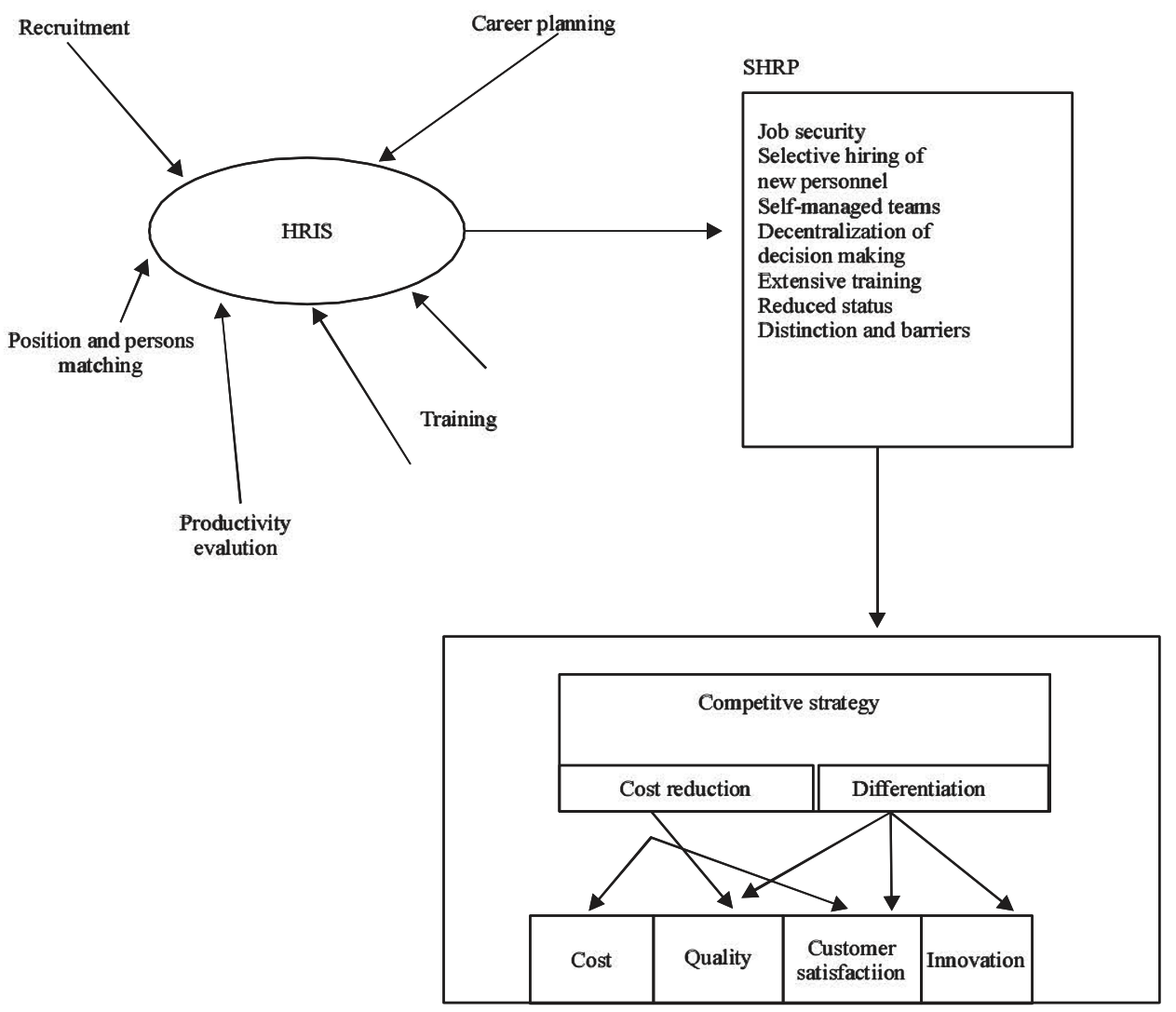

Fig. 2: Proposed model 
company. It will chart future career paths for all categories of employees by specifying ranges of assignments and training opportunities for various career intervals.

Productivity evaluation: It involves creating output measures of performance to be used in evaluating the productivity of specific programs, offices or position.

Position classification: This variable will provide an automated information system for position classification programs. It would entail the direct inputs and maintenance of position data by the position classification staff, automated monitoring of the job content and the level of positions and computerized retrieval of data on classes or series of positions for evaluation.

Position/person matching: Which will establish a computerized process for the direct correlation of position requirements against personal qualifications and preferences for possible assignments. It creates mechanism for scrolling all employees as candidates for specific jobs and can identify either atop range of candidates for specific position or a top range of potential positions for single individual.

Recruitment: This variable provides data for the analysis and evaluation of recruitment efforts. It will monitor the qualifications and special characteristics of new employees by various functional categories and analyze retention and development trends.

Training: A systematic and continuous process for the purpose of providing employees with knowledge, providing them with the required skills and abilities that they need while performing their work according to the specified objectives and developing the behavioral aspects that are compatible and necessary to perform the best for them. It is defined as a set of programs and methods used by a company to develop its human resource capabilities to enhance their skills and change their behavior trends to achieve a given tasks.

\section{CONCLUSION}

The implication of any given personnel decision may sometimes seems infinite. HRIS as integrated personnel management information systems could automatically chart the interactions of any given decisional options and report them as options to the decision maker. Therefore, this framework can be adapted by any organization to satisfy its own requirements. In addition, the framework for pro is also simple and could be used for most organizations. The fram ework shows that human resource information systems is one of main features that help to provide the basic personnel information regardless the nature of the organization. The researcher tried to build a framework for acquiring personal management information systems which can be used almost for most large organizations. This framework is simple, easy and comprehensive. Hopefully, that this framework will shed some light for policy makers allowing them to plan effectively for their human resources.

\section{REFERENCES}

Aswathappa, K., 2002. Human Resource Management. 3rd Edn., McGraw-Hill, New York, USA.,

Conner, J. and D. Ulrich, 1996. Human resource roles: Creating value, not rhetoric. People Strategy, 19: 38-49.

Mondy, W.R. and R.M. Noe, 2005. Human Resource Management. 9th Edn., Pearson Education, New Jersey.

Porter, M., 1998. Competitive Advantage: Creating and Sustaining Superior Performance. Free Press, New York, USA., Pages: 592.

Wright, P.M. and W.R. Boswell, 2002. Desegregating HRM: A review and synthesis of micro and macro human resource management research. J. Manage., 28: $247-276$. 